\title{
INTRODUCTION \\ The importance of understanding the medicolegal climate in neurosurgery
}

\author{
Bharat Guthikonda, MD, MBA, ${ }^{1}$ Catherine A. Mazzola, MD, ${ }^{2}$ Michael P. Steinmetz, MD, ${ }^{3}$ \\ Joseph S. Cheng, MD, ${ }^{4}$ Jason D. Stacy, MD, ${ }^{5}$ Asdrubal Falavigna, MD, $\mathrm{PhD},{ }^{6}$ and \\ Richard N. W. Wohns, MD, JD, MBA \\ 'Department of Neurosurgery, LSU Health Sciences Center, Shreveport, Louisiana; ${ }^{2}$ New Jersey Pediatric Neuroscience \\ Institute, Morristown, New Jersey; ${ }^{3}$ Department of Neuroscience, The MetroHealth System, Cleveland, Ohio; ${ }^{4}$ Department \\ of Neurosurgery, University of Cincinnati, Ohio; ${ }^{5}$ Department of Neurosurgery, North Mississippi Medical Center, Tupelo, \\ Mississippi; ${ }^{6}$ Department of Neurosurgery, University of Caxias do Sul, Brazil; and ${ }^{7 N}$ NeoSpine, Puyallup, Washington
}

$\mathrm{N}$ EARLY all neurosurgeons will be affected by the medicolegal process at some point in their career. Many of us are not well prepared and not as educated about this aspect of neurosurgery as we are about skull base anatomy or pedicle screw placement. There are not many articles dedicated to the medicolegal and socioeconomic aspects of neurological surgery. We are proud to present to you this month's issue of Neurosurgical Focus, which is specifically dedicated to enhance our knowledge and understanding of the nuances of these topics. The Accreditation Council for Graduate Medical Education recognizes the importance of medicolegal and socioeconomic education for neurosurgery residents. The American Association of Neurological Surgeons and Congress of Neurological Surgeons have supported the Joint Section of the Council of State Neurosurgical Societies (CSNS) for decades. The CSNS is the grass roots organization formed by elected representatives from every state, with representatives from our parent organizations, and other members, where bi-annually, socioeconomic and medicolegal topics are actively discussed and debated. Many of the articles submitted address relevant topics that are hotly debated at the CSNS meetings. In truth, we received so many excellent articles, and we wish that we could have accepted all of them. This edition has been organized with sections describing general medicolegal overview, the international medicolegal milieu, medicolegal issues in spinal neurosurgery, and cranial neurosurgical medicolegal issues. We encourage all of you to read these articles and discuss their content locally in your residency training programs, in your hospitals, and at your state society meetings. We hope that by reading these papers, we are able to provide relevant and informative content that is useful for all neurosurgeons, at all stages of their careers.

https://thejns.org/doi/abs/10.3171/2020.8.FOCUS20765

\section{Disclosures}

Dr. Steinmetz reports being a consultant to Globus, receiving honoraria from Stryker and Globus, and receiving royalties from Zimmer and Elsevier. Dr. Wohns reports being a consultant to Medtronic, SeaSpine, and Alphatec.

\section{Correspondence}

Bharat Guthikonda: bguthi@1suhsc.edu. 